\title{
Structure-property relationships in polymer nanocomposites based on cross-linked polyurethanes and carbon nanotubes
}

\author{
E.A.Lysenkov ${ }^{1}$, Z.O.Gagolkina ${ }^{2}$, E.V.Lobko ${ }^{2}$, \\ Yu.V.Yakovlev , S.D.Nesin ${ }^{2}$, V.V.Klepko ${ }^{2}$ \\ ${ }^{1}$ V.Sukhomlynskiy Mykolayiv National University , \\ 24 Nikol'ska Str., 54030 Mykolayiv, Ukraine \\ ${ }^{2}$ Institute of Macromolecular Chemistry, National Academy of Sciences of \\ Ukraine, 48 Kharkivske Shosse, 02160 Kyiv, Ukraine
}

Received May 8, 2015

The results of experimental and calculation researches of structure, electric and thermophysical characteristics of polymer nanocomposites based on cross-linked polyurethanes (CPU) and carbon nanotubes (CNT) are presented. It is shown that the CPU-CNT systems have a structure with two fractal levels. It is discovered that the CPU-CNT nanocomposites show a percolation behavior, and the concentration dependence of electric- and heat-conductivity are well described in the framework of scaling approach. It is shown that a percolation threshold for these systems is $0.6 \%$. Formation of the percolation net from CNT, when the content of nanotubes is $0.6 \%$, was confirmed by the optical microscopy results.

Keywords: cross-linked, carbon nanotubes, percolation, fractal structure, scaling.

Представлены результаты экспериментальных и расчетных исследований структуры, электро- и теплофизических характеристик полимерных нанокомпозитов на основе сетчатого полиуретана (СПУ) и углеродных нанотрубок (УНТ). Установлено, что системы СПУ-УНТ имеют двухуровневую фрактальную структуру. Показано, что нанокомпозиты СПУ-УНТ проявляют перколяционное поведение, а концентрационная зависимость электро- и теплопроводимости хорошо описывается в рамках скейлингового подхода. Обнаружено, что порог перколяции для данных систем составляет 0,6\% Образование перколяционной сетки из УНТ при содержании нанотрубок 0,6 \% подтверждается данными оптической микроскопии.

Зв'язок між структурою та властивостями у полімерних нанокомпозитах на основі сітчастих поліуретанів та вуглецевих нанотрубок. Е.А.Лисенков, З.О.Гаголкіна, Є.В.Лобко, Ю.В.Яковлев, С.Д.Несін, В.В.Клепко.

Представлено результати експериментальних і розрахункових досліджень структури, електро- та теплофізичних характеристик полімерних нанокомпозитів на основі сітчастих поліуретанів (СПУ) та вуглецевих нанотрубок (ВНТ). Встановлено, що системи СПУ-ВНТ мають дворівневу фрактальну структуру. Показано, що нанокомпозити СПУ-ВНТ проявляють перколяційну поведінку, а концентраційна залежність електрота теплопровідності добре описується у рамках скейлінгового підходу. Виявлено, що поріг перколяції для даних систем становить $0.6 \%$. Утворення перколяційної сітки 3 ВНT при вмісті нанотрубок 0.6 \% підтверджується даними оптичної мікроскопії. 


\section{Introduction}

Polymer nanocomposites based on elastomers with high electric and heat conductivity are used in many areas of production: from sealant between pipes for transport explosive gases to electric and heat conductive coatings and electromagnetic screening of mobile electronics [1]. In most cases, for creation of such elastomeric nanocomposites matrices are used that are based on polyurethane (PU) and various fillers such as carbon black [2], metallic particles [3] or carbon fibers [4]. Percolation thresholds for such systems are 5-10\%.

In the recent years nanocomposite materials based on carbon nanotubes (CNT) attired large attention of researchers due to their unique properties and a wide spectrum of their practical application [5]. These nanocomposites have unique electric and thermodynamic properties due to formation of percolation clusters of CNT in dielectric media. In general, the percolation threshold is observed at extraordinarily small concentrations of CNT [6]. The low percolation thresholds are noted not only for the systems based on polymers, but for nanocomposites based of liquid crystals [7] and liquids [8]. Such comparatively low percolation threshold is explained by the high shape anisometry of CNT, which are characterized by large values of their aspect ratio (200-1000).

PU materials of different structure used for creation of composites with nanotubes have been described in literature. For example, the authors of work [9] observed, for PU filled by single walled CNT, the increase in electric conductivity level from $1.2 \cdot 10^{-14}$ to $2.2 \cdot 10^{-4} \mathrm{~S} / \mathrm{cm}$ when the content of nanofiller reached $20 \%$. The presence of percolation transition and effects of the formation temperature of PU-CNT on the concentration of the percolation threshold were reported in [10]. In particular, it is shown that forming of composites at higher tem- peratures reduces the percolation threshold (at $210^{\circ} \mathrm{C}$ and $190^{\circ} \mathrm{C}$ the percolation threshold occurred at 3 and $4 \%$ of CNT in the system, respectively). In this case the electric conductivity at the room temperature for different concentrations of CNT is in the range of $10^{-5}-10^{-6} \mathrm{~S} / \mathrm{cm}$. The levels of conductivity at $\mathrm{CNT}$ content of 0.5 and $10 \%$ are $8.9 \cdot 10^{-10} \mathrm{~S} / \mathrm{cm}$ and $1.2^{.10-6} \mathrm{~S} / \mathrm{cm}$, respectively, for nanocomposites based on PU and multi walled CNT modified by the alkyl groups [11].

From the literature review it can be shown that nanocomposites with different structure of polymer matrix and nanofiller are characterized by substantially different values of electric and heat conductivity and percolation thresholds. Therefore the purpose of this work was establishment of structure-properties relationships in polymer nanocomposites based on cross-linked polyurethanes and carbon nanotubes.

\section{Experimental}

For our studies, we used systems based on cross-linked polyurethanes (CPU) and carbon nanotubes. CPU were synthesized in two stages. At the first stage the prepolymer on the base of polypropylene glycol with molecular mass 1000 (PPG-1000) and toluene diisocyanate (TDI) $(2,4-/ 2,6$-isomers $=80 / 20$ ) was synthesized (Fig. 1). PPG1000 was dried under the pressure of $300 \mathrm{~Pa}$ at $393 \mathrm{~K}$ during $3 \mathrm{~h}$. The valence ratio $\mathrm{PPG} / \mathrm{TDI}=1 / 2$. The synthesis of prepolymer was held at $393 \mathrm{~K}$ during $1.5 \mathrm{~h}$, with amount of isocyanate groups $5.9 \%$. The reaction path was controlled for decreasing of the number of isocyanate groups according to [12]. At the second stage the prepolymer was cross-linked with thimethylol propane (TMP) used as cross-linking agent (Fig. 2).

TMP was dried under pressure at 313$315 \mathrm{~K}$. The TMP was solved in prepolymer<smiles>CCOC(C)CO[C@H](C)OC(C)COC(=O)Nc1cccc(N=C=O)c1</smiles>

Fig. 1. The synthesis reaction of prepolymer based on PPG-1000 and TDI. 


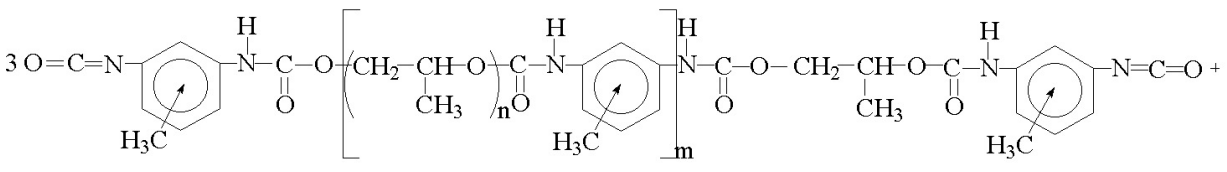

$+2 \mathrm{C}_{2} \mathrm{H}_{5} \mathrm{C}\left(\mathrm{CH}_{2} \mathrm{OH}\right)_{3} \longrightarrow$

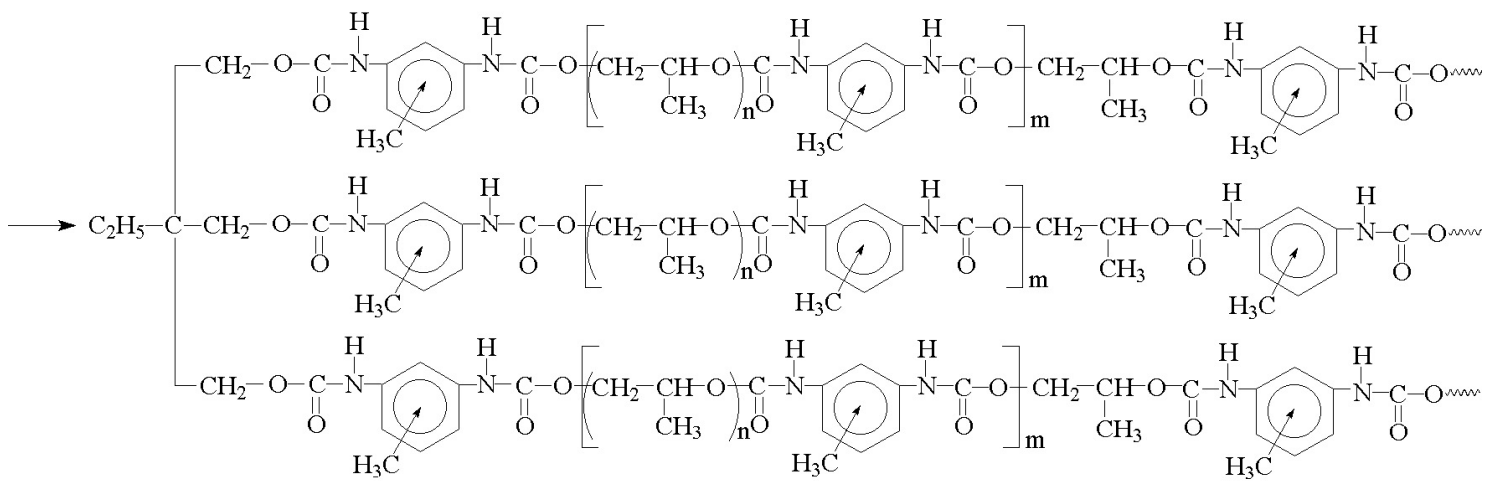

Fig. 2. Reaction of the cross-linkage of prepolymer by the TMP with the formation of CPU. The fragment of CPU with cross-linkage of junction nodes.

at 346-348 $\mathrm{K}$ in the oil bath during $20 \mathrm{~min}$ with continuous mixing in dried argon atmosphere. The valence balance prepolymer $/ \mathrm{TMP}=3 / 2$. The reaction path was controlled as in [12] or by IR-spectrometry (a Tensor-37 Bruker with Furier transforms).

Multi-walled CNT ("Specmash" Ltd., Ukraine) were made by method of CVD (chemical vapour deposition) at $0.1 \%$ of mineral admixtures. Specific surface area is $190 \mathrm{~m}^{2} / \mathrm{g}$, external diameter is $20 \mathrm{~nm}$, length is 5-10 $\mu \mathrm{m}$ [13]. Specific conductivity of pressed CNT (at pressure $15 \mathrm{TPa}$ ) along the axis of compression is $10 \mathrm{~s} / \mathrm{cm}$. The CNT content in polymer nanocomposites was varied from $0.02 \%$ to $1 \%$.

The carbon nanotubes were added in reaction mass as the dispersion in dichloromethane $\left(\mathrm{CH}_{2} \mathrm{Cl}_{2}\right)$. The dispergation of CNTs was carried out in two stages using sonicator UZN-22/44 at dispergation frequency $22 \mathrm{kHz}$. In the first stage the dispergation of carbon nanotubes was done in $\mathrm{CH}_{2} \mathrm{Cl}_{2}(50 \%$ of the total mass of the sample) for $2.5 \mathrm{~min}$. In the second stage dispersion of CNTs was cooled to room temperature and was added to the reaction mass. The dispergation was continued for $2.5 \mathrm{~min}$. The formation of CPU-CNTs was carried out in Petri dishes at $318 \mathrm{~K}$. The solvent residues were removed from films by vacuuming them to constant weight.

Small angle X-ray scattering (SAXS) plots were obtained in a vacuum Kratky type chamber, in the radiation of copper anode, monochromatized by a total external reflection and nickeliferous filter [14]. A survey was conducted in the mode of frequent step-by-step scanning of scintillation detector in the range of scattering angles from $0.03^{\circ}$ to $4.0^{\circ}$ satisfying the sizes of wave vector, $q$, from $0.022 \mathrm{~nm}^{-1}$ to $2.86 \mathrm{~nm}^{-1}(q=4 \sin \pi \theta \lambda, \theta$ is a half of scattering angle, $\lambda$ is a wave-length of $\mathrm{X}$-ray radiation). Treatment of SAXS curves was carried out with the use of the FFSAXS program [15].

Electric properties of nanocomposites are investigated by the method of impedance spectroscopy, realized on a base of impedancemeter Z-2000 (Russia). A sample is placed between electrodes of the cell and real $\left(Z^{\prime}\right)$ and imaginary $\left(Z^{\prime \prime}\right)$ parts of impedance were meadured. From the frequency dependence of complex impedance we determined, using the method described in [16], the direct current (DC) conductivity $\sigma_{d c}=d / S R_{d c}$, where $S$ is the sample area, $d$ is the sample thickness. The measurements were carried out at a room temperature in the frequency range $1 \mathrm{~Hz}-2 \mathrm{MHz}$.

The thermal conductivity was measured by the method of dynamic calorimetry with an IT- $\lambda-400$ meter (Russia, measurement accuracy $\pm 5 \%$ ) with a modified cell [17]. The instrument was calibrated with the aid of thermal conductivity measurements on reference samples made of fused quartz and 
copper. Measurements were carried out using a monotonous regime method. The specific thermal conductivity of the sample, $\lambda$, was calculated as $\lambda=h / R_{s}$, where $h$ is the sample thickness, $R_{s}$ is thermal resistance.

Transmittance microphotographs of CPU were obtained using an optical XY-B2 microscope equipped with an ICM 532 digital video eyepiece and an AMCAP/VIDCAP (Microsoft) system of image processing. The probed samples were placed in a glass cell with thickness of $100 \mu \mathrm{m}$.

\section{Results and discussion}

\subsection{Structure of nanocomposites by $S A X S$}

The SAXS technique allows determination of the morphological features of nanocomposites based on polyurethanes at the level of microphase separation [18], on the supramolecular structural level. For the analysis of nanocomposites in the frame of fractal-cluster structure organization, the SAXS curves of probed pure CPU and systems of CPU-CNT are presented on Fig. 3 in double logarithmic coordinates.

The interference maximum of diffuse type with position $q_{m}=0.17 \AA^{-1}$, which is characteristic for segmented PU, is observed for pure CPU (Fig. 3, curve 1). It shows the presence of periodicity in the spatial location of areas of heterogeneous polymer structure with similar electronic densities in the form of alternation of hard and flexible blocks of PU.

Fig. 3 shows a linear decrease of scattering intensity (in double logarithmic coordinates) for pure CPU. This decrease is observed practically in all the regions of wave vector $q$ change and is characterized by the single value of slope tangent of angle, which equal -3.5 , that suggests the single Porod's power law regime of scattering $\left(I \sim q^{-D}\right)$ [19]. Such type of SAXS curve in double logarithmic coordinates for investigated CPU specifies the scattering by the system with one level of fractal aggregates or clusters.

On the SAXS curve for the CPU-CNT system (Fig. 3) there are two linear regions with the different slopes (two Porod's power law regimes of scattering), which are divided by a small nonlinear area. Such type of the SAXS curve specifies the existence of two types of fractal clusters, with two levels of fractal organization of structure [20]. The first level has the spatial scales of about $10-30 \mathrm{~nm}$ and represents the sizes of

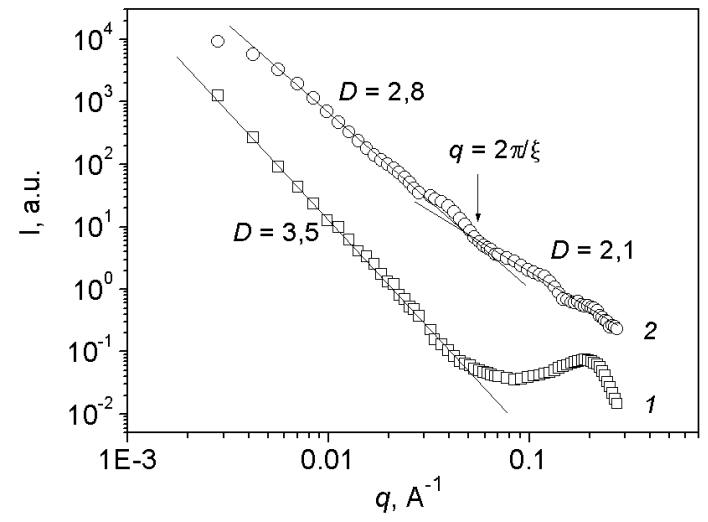

Fig. 3. SAXS curves for investigated samples: 1 - pure CPU; 2 - CPU+1 \% CNT.

individual nanotubes. The second level corresponds to the transversal sizes of aggregates (bundles) which consist of the poorly cased individual nanotubes.

The slope of the linear region of the SAXS curve, which equals 2.1 for the random distributed nanotubes in the polymer matrix, is explained by the scattering from mass fractal aggregates consisting of CNT [19].

Using the approach proposed in [21], from the values of wave vector for the crossover in the SAXS curve it is possible to define the mesh size $(\xi)$ of the formed network, which consists of CNT. $\xi$ is the distance between the junctions of the associated rigid rod network. The calculated mesh size is equal to $12.5 \mathrm{~nm}$. It has a good correlation with the value $\xi=15 \mathrm{~nm}$ for surfactant-stabilized single-wall carbon nanotubes in water [21]. This effect testifies on formation of untight aggregates from individual CNT in the matrix. Such character of mass fractal organization and friability of CNT aggregates considerably affects the percolation behavior of thermal and electrophysical properties of nanocomposites based on CPU and CNT.

\subsection{Electrical conductivity of the CPU-CNT nanocomposites}

Fig. 4 represents the concentration dependence of DC conductivity for the investigated systems of CPU-CNT. The concentration dependence of conductivity is of nonlinear character. When the content of the filler increases, the conductivity of the systems slowly grows to the concentration of nanofiller equal to $0.6 \%$. Rapid change of conductivity, which can be related to the process of percolation, is observed in the concentration range $0.6-0.8 \%$. When the 


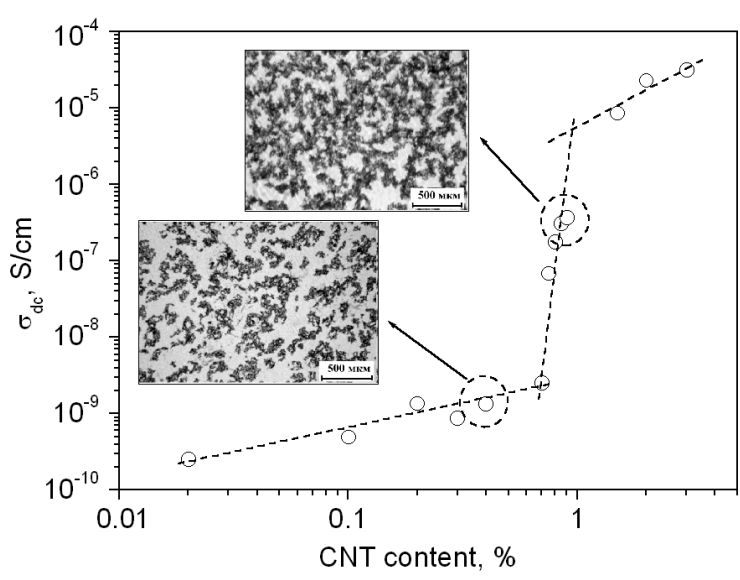

Fig. 4. DC conductivity vs. CNT content for the CPU-CNT system at $T=293 \mathrm{~K}$.

CNT content is $0.9 \%$, the conductivity of the system is higher by more than on two orders as compared with the conductivity before the percolation threshold.

The polymeric systems filled with CNT that have the conductive properties are characterized, due to flexibility and nanosize of nanotubes, by a very low critical percolation concentration (percolation threshold). A dielectric-conductor transition is partly described in the frame of percolation theory which is usually utillized for establishment of relation between the microstructure of these systems and their physical properties [22]. According to the percolation theory, in the systems after the percolation threshold, relationship between conductivity and nanofiller content can be described by the following scaling law [23]:

$$
\sigma \propto\left(p-p_{c}\right)^{t} \text { for } p>p_{c},
$$

where $\sigma$ is the conductivity of the system, $p$ is the mass concentration of conducting nanofiller particles, $p_{c}$ is the critical nanofiller concentration at the percolation transi

tion (percolation threshold), $t$ is the exponent index - a critical index of conductivity, which mainly depends on the topological dimensionality of the system and does not depend on the structure of particles which form clusters and from their interaction.

The values of percolation threshold $p_{c}$ and critical index $t$, which characterize structural organization of the nanofiller in the nanocomposite and the structure of clusters, are determined from experimental data using the least-squares method and Eq. (1) (Fig. 5a). The percolation threshold value for the system of CPU-CNT is $0.6 \%$, and $t=2.25 \pm 0.08$, which testifies to formation of a three-dimensional spatial percolation net from the clusters of nanotubes [22]. Such low $p_{c}$ values are very close to the values $\left(p_{c}=0.45 \%\right)$ obtained for the PPG-CNT system [24], which has very similar chemical nature with the investigated system based on CPU and consists of PPG fragments. The low value of percolation threshold for this system is explained by the large aspect ratio of CNT (length/diameter ratio is approximately 200-300) [25].

The value of critical index $t$ is higher than the theoretical value $t \approx 2$. It can be explained by non-statistical distribution of the conducting phase in the polymer matrix, because the value $t \approx 2$ foresees the random distribution of conducting particles in a dielectric media [22]. Such unstatistical arrangement is explained by the processes of CNT aggregation after preparation of these systems, with formation of conducting net due to attraction between individual CNT.

The electric conductivity of the system increases to the value $6 \cdot 10^{-6} \mathrm{~S} / \mathrm{cm}(0.9 \% \mathrm{CNT})$ and practically does not change with the subsequent increase of CNT content after achievement of the percolation threshold. However, the conductivity of nanocomposite is much lower than conductivity of CNT $\left(\sigma_{\mathrm{CNT}}=10 \mathrm{~s} / \mathrm{cm}\right)$. Such difference in conductivities is explained by the fact that nanotubes dispersed in the polymeric matrix do not form direct contacts between themselves. Due to wetting processes, a thin polymer interlayer appears between the neighboring CNT, resulting in the decrease in conductivity. In this case, when nanotubes are separated by polymer molecules with no direct contacts between them, the transfer of charges can be realized by two mechanisms: hopping and tunneling. The first mechanism consists in hopping of electrons from one nanotube onto another, and this process is similar to the phenomenon of thermoelectron emission. Such mechanism can be realized only when the thickness of polymer film between CNT is few nanometers and in the presence of electrons with considerable kinetic energy. When the thickness of non-conducting film between CNT is less than $5 \mathrm{~nm}$, in obedience to the laws of quantum mechanics there is nonzero probability to find out an electron at the other side of the film, so, electrons can pass through this non-conducting barrier even without acquisition of extra energy. Such 


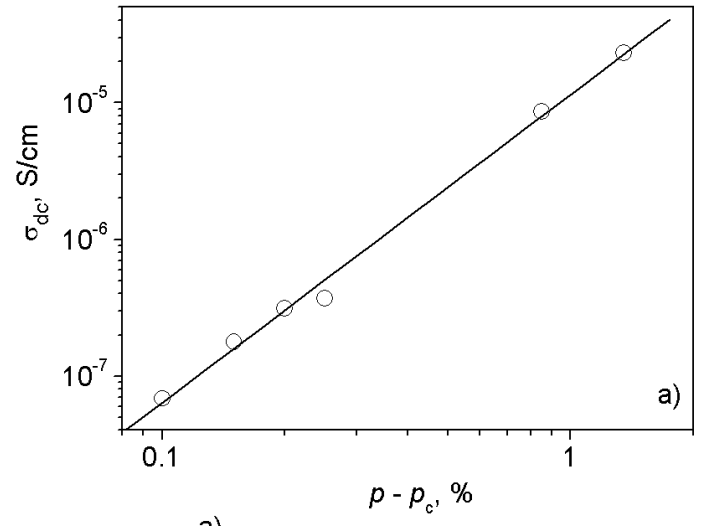

a)

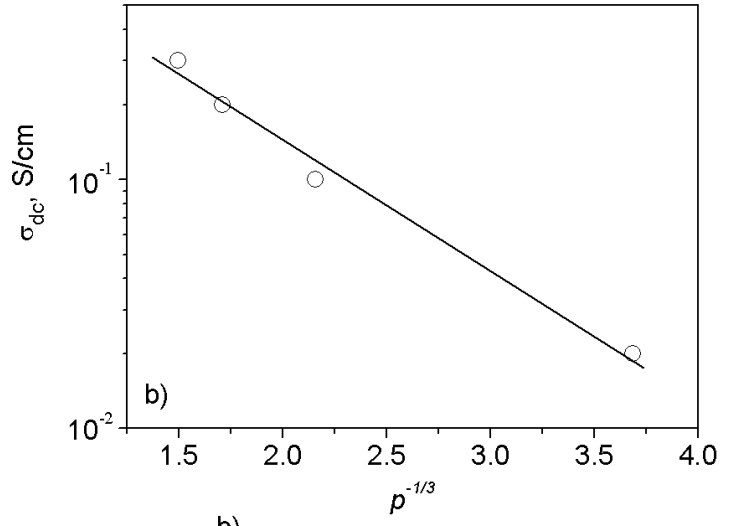

b)

Fig. 5. Dependences of DC conductivity (in logarithmic scale) in coordinates of Eq. (1) (a) and Eq. (2) (b) for the CPU-CNT system. Solid line - linear approximation of Eq. (1) and Eq. (2), respectively.

mechanism of transfer of charge is called tunneling.

With random distributing of nanofiller in a non-conducting polymer matrix, conductivity at this temperature is carried out mainly by the mechanism of tunneling, and the width of potential barrier is determined as $\omega \propto p^{-1 / 3}$. The method of authentication of tunneling mechanism offered in nanofilled systems was proposed in [26]. According to this approach, the conductivity of the system after the percolation threshold depending on filler content changes as:

$$
\log \sigma \propto p^{-1 / 3} .
$$

Fig. 5b shows the dependence of conductivity from CNT content for the investigated systems in the co-ordinates of equation (2). From Fig. 5b evidently, that experimental data is described within the framework of dependence (2). This fact testifies that the basic mechanism of charge transfer in this system is a tunneling mechanism [27].

\subsection{Heat conductivity of the CPU-CNT nanocomposites}

One of basic thermophysical descriptions of nanocomposite materials is a heat conductivity, which depends both on a structure and physical condition of polymer matrix and from content, form and character of nanofiller. The level of heat conductivity of polymer nanocomposites is low enough, as basic contribution to the general heat conductivity is given by the polymer matrix $(\lambda \approx 0.1 \mathrm{~W} /(\mathrm{m} \cdot \mathrm{K}))$. It is known that the heat conductivity of polymer nanocomposites depends not only on the heat conductivity of the filler, concentration and his propensity to formation of own structures in composi- tion material but also on the heat conductivity of polymer matrix which can change its structure under influence of the filler.

Fig. 6 presents the experimental results of the heat conductivity dependence on the filler's content for the CPU-CNT nanocomposites. From Fig. 6, it is evident that concentration dependence of heat conductivity has nonlinear character. This dependence can be divided into two regions: "I" is the region (from 0 to $0.5 \%$ CNT), where the heat conductivity of nanocomposite depends only on the structure of polymer matrix; "II" is the region (from 0.5 to $3 \% \mathrm{CNT}$ ), where growth of heat conductivity is related to the contribution of CNT to the heat conductivity of nanocomposite, because CNT have much higher heat conductivity coefficient as compared to the polymer matrix.

Consequently, changes of heat conductivity at small concentrations of the filler (region I, Fig. 6) are related to the local compression of polymer matrix under influence of randomly distributed individual CNT. The subsequent increase of filler's concentration results in decrease of heat conductivity. The effect of heat conductivity decrease of the system at $0.3-0.5 \%$ filler concentrations can be explained by scattering of phonons on "nanotube-polymer" interface [28]. In addition, the indicated concentration range is possibly characterized by the presence of nanopores, which favors the decrease of heat conductivity of nanocomposite due to the decrease of polymer heat conductivity and additional energy dissipation on heterogeneities of the system [29].

The increase of heat conductivity with the subsequent increase of the filler's content (region II, Fig. 6) is related to the con- 


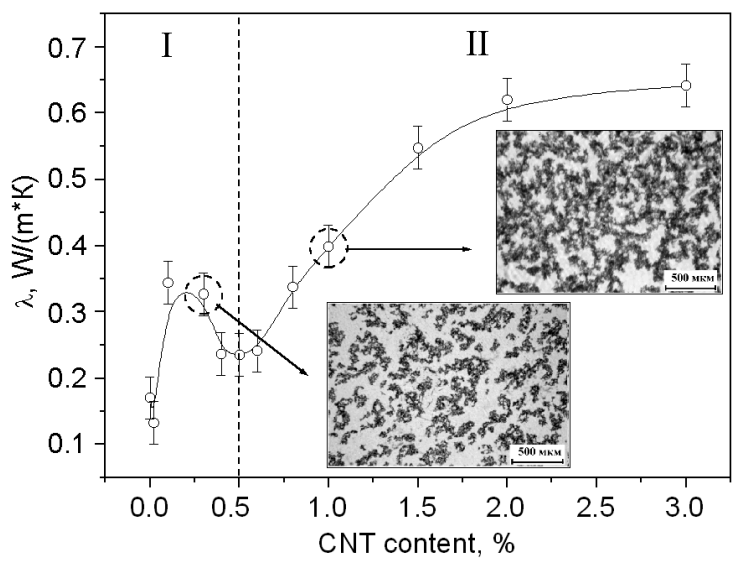

Fig. 6. Heat conductivity vs. CNT content for the CPU-CNT system at $T=298 \mathrm{~K}$.

tribution of CNT, which have higher heat conductivity as constituent of the nanocomposite. In comparing to the jump of conductivity by a few orders at $1 \%$ of CNT content, the heat conductivity of the CPU-CNT system grows by up to two times. The presence of the developed "polymer-nanotube" interface hinders the achievement of the values of heat conductivity of nanocomposite that would be commensurable with the value of CNT heat conductivity. The main contribution to low heat conductivity of nanocomposite comes from the energy dissipation on contacts between CNT [28]. The rapid increase of the heat conductivity coefficient when the CNT concentration is $0.6 \%$, is related to the process of percolation, at which nanotubes form a heat-conducting net in the polymer matrix.

According to the percolation theory, which examines the random distributing of heat-conducting component in a non-conducting media, it is possible to describe the dependence of the heat conductivity coefficient $\left(\lambda_{e f}\right)$ of the nanocomposite on CNT content using the following equation [22]:

$$
\lambda_{e f} \propto\left(p-p_{c}\right)^{k}, \quad \text { for } p>p_{c},
$$

where $p$ is the concentration of heat-conducting nanofiller (CNT), $p_{c}$ is a critical concentration of nanotubes (percolation threshold), $k$ is a critical index of heat conductivity.

Applying a least-squares method and Eq. (3) for describing of experimental data of concentration dependence of heat conductivity (Fig. 6), we determined the values of percolation threshold $p_{c}$ and critical index $k$, which characterize structural organization of the nanofiller in the composite and depend on his size and form. The value of percolation threshold for the CPU-CNT system is $0.6 \%$, and $k=0.28 \pm 0.03$. The value of the percolation threshold appeared less than its values for most polymer-CNT systems. The percolation threshold is $2.2 \%$ for the system of ethylene terpolymer-CNT [30], the percolation threshold is $0.72 \%$ for the system of PE-CNT [17]. Such disagreements are explained by different methods of polymer nanocomposites preparation, sizes and type of nanotubes and testify to different processes of their aggregation.

\section{Conclusions}

The structure, electric and heat conductivity of the systems based on CPU and CNT have been studied. The probed systems are analyzed within the framework of the percolation theory and the fractal approach. The existence of two types of fractal clusters and two levels of fractal organization of structure in the CPU-CNT systems was discovered by the method of X-ray scattering. The first level represents the sizes of individual nanotubes, the second level specifies on the transversal sizes of aggregates (bundles) which consist of the poorly cased individual nanotubes. It is shown that such character of mass fractal organization and friable CNT aggregates considerably influences the features of percolation behavior of thermo- and electrophysical properties of CPU-CNT nanocomposites. As a result of the electric conductivity studies, the percolation threshold for these systems, which is $0.6 \%$, was certain. The critical index $t=2.25$, which testifies to formation of three-dimensional spatial percolation net from the clusters of nanotubes and considerable CNT aggregation after preparation of samples was determined using the scaling approach. It is discovered that nonconducting polymer film appears between individual nanotubes, due to wetting in CPU-CNT systems. As a result of it, alongside with for the charge transport through direct contacts between nanotubes, the additional tunneling mechanism is realized. It is shown that the heat conductivity of the CPU-CNT system shows a percolation behavior and well described within the framework of the scaling approach. The percolation threshold for a heat conductivity is $0.6 \%$. The value of the percolation threshold obtained as a result of electric and heat conductivity measurements is confirmed by microscopic researches. It is discovered that the percolation cluster from nanotubes appears at $0.6 \% \mathrm{CNT}$ content. 


\section{References}

1. H.Koerner, W.Liu, M.Alexander, P.Mirau et al., Polymer, 46, 4405 (2005).

2. S.G.Chen, J.W.Hu, M.Q.Zhang et al., Carbon, 42, 645 (2004).

3. Z.Guo, S.Park, H.T.Hahn et al., J.Appl.Phys., 101, 09M511 (2007).

4. H.J.Zo, S.H.Joo, T.Kim et al., Fibers and Polymers, 15, 1071 (2014).

5. A.Moisala, Q.Li, I.A.Kinloch et al., Compos. Sci. and Technol., 66, 1285 (2006).

6. E.A.Lysenkov, V.V.Klepko, V.M.Golovanets et al., Ukr. J.Phys., 59, 906 (2014).

7. L.N.Lisetski, N.I.Lebovka, S.V.Naydenov et al., J. Mol. Liq., 164, 143 (2011).

8. O.Deriabina, N.Lebovka, L.Bulavin et al., Physica E: Low-dimens. Syst. and Nanostruct., 59, 150 (2014).

9. L.Zunfeng, B.Gang, H.Yi et al., Carbon, 45, 821 (2007).

10. R.Zhang, A.Dowden, H.Deng et al., Compos. Sci. and Technol., 69, 1499 (2009).

11. J.Wang, H.Xu, D.Yang et al., Compos. Fibers and Polymers, 14, 571 (2013).

12. Technical Condition 113-03-413-89, Isocyanates. The Method of Mass Content of Isocyanate Groups (1989).

13. A.V.Melezhyk, Yu.I.Sementsov, V.V.Yanchenko, Prikl. Khim., 78, 938 (2005).

14. Yu.S.Lipatov, V.V.Shilov, Yu.P.Gomza, EN.E.Kruglyak, The Methods of X-ray Diffraction for the Investigation of Polymer Systems. Naukova Dumka, Kiev (1982) [in Russian].
15. C.G.Vonk, FFSAXS's Program for the Processing of Small-Angle X-ray Scattering Data, DSM, Geleen (1974).

16. A.Kyritsis, P.Pissis, J.Grammatikakis, $J$. Polymer Sci.: Part B: Polymer Phys., 33, 1737 (1995).

17. R.V.Dinzhos, N.M.Fialko, E.A.Lysenkov, $J$. Nano-Electron. Phys., 6, 01015 (2014).

18. N.Cameron, J.M.G.Cowie, R.Ferguson et al., Europ. Polym. J., 38, 597 (2002).

19. M.C.Garcia-Gutierrez, A.Nogales, J.J.Hernandez et al., Opt. Pura Apl., 40, 195 (2007).

20. G.Beaucage, J.Hyeonlee, Se.Pratsinis et al., Langmuir, 14, 5751 (1998).

21. L.A.Hough, M.F.Islam, B.Hammouda et al., Nano Letters, 6, 313 (2006).

22. D.Stauffer, A.Aharony, Introduction to Percolation Theory, Taylor and Francis, London (1994).

23. S.Kirkpatrick, Phys.Rev.Lett., 27, 1722 (1971).

24. E.A.Lysenkov, Y.V.Yakovlev, V.V.Klepko, Ukr.Phys.J., 58, 378 (2013).

25. J.Zhang, M.Mine, D.Zhu et al., Carbon, 47, 1311 (2009).

26. M.T.Connor, S.Roy, T.A.Ezquerra et al., Phys. Rev. B, 57, 2286 (1998).

27. E.A.Lysenkov, V.V.Klepko, J.Nano-Electron. Phys., 5, 03052 (2013).

28. Y.Xu, G.Ray, B.Abdel-Magid, Compos.A, 37, 114 (2006).

29. O.M.Garkusha, S.M.Mahno, G.P.Pryhodko et al., Chem. Phys. Technol. Surf., 1, 103 (2010).

30. B.-W.Kim, S.-H.Park, R.S.Kapadia et al., Appl.Phys. Lett., 102, 243105 (2013). 